\title{
Analisis Penggunaan Tata Bahasa Indonesia dalam Penulisan Ragam Kalimat: Studi Kasus Pemelajar Kelas 11 SMA Cristal Dili
}

\author{
Yutriani Andhika*) \\ Pengajar BIPA Lokal Timor Leste \\ *) Corresponding author: Dili, Negara; Timor Leste \\ andhikayutriani1@gmail.com
}

\begin{abstract}
Writing a variety of sentences in Bahasa Indonesia must be following Indonesian grammar rules. The purpose of this writing is to describe the simple Indonesian grammar, as well as to see its implementation on the teaching of class 11 BIPA in Cristal Dili High School. Analysis of the use of Indonesian grammar in writing a variety of sentences is done by a qualitative descriptive method. As a tool to describe Indonesian grammar used in Indonesian grammar according to the rules of the grammar of Bahasa Indonesia, enhanced spelling, and dictionary of the Indonesian language. The Indonesian standard of writing sentences includes proper word selection, effective sentence, punctuation usage, and capitalization. The results showed that the infirmity of writing sentences using Bahasa Indonesia was the fault of ineffective punctuation, diction, and sentences.
\end{abstract}

Key Words: Indonesian grammar, writing ability, BIPA.

Thiswork is licensed under a Creative Commons Attribution-ShareAlike 4.0 International License

\section{Pendahuluan}

Disadari bahwa penulisan ragam kalimat dapat mengubah maksud dari bahasa itu sendiri. Misalnya, kalimat yang digunakan untuk sebuah instruksi akan berbeda dengan kalimat yang digunakan untuk meminta bantuan. Dalam penggunaannya, bahasa Indonesia dibedakan ke dalam ragam formal, semi formal, dan nonformal.

Pada umumnya tata bahasa bersifat normatif, yaitu tata bahasa tersebut tersusun berdasarkan gejala-gejala bahasa yang umum digunakan dalam suatu kelompok masyarakat. Dari waktu ke waktu bahasa akan terus berkembang, oleh karena itu tata bahasa normatif harus bersifat deskriptif.

Menurut Keraf (Misriyah, 2011:1), tata bahasa merupakan suatu himpunan dari patokan-patokan dalam struktur bahasa. Struktur bahasa itu meliputi tata bunyi, tata bentuk, tata kata, tata kalimat, dan tata makna. Menurut Kamus Besar Bahasa Indonesia (2001), tata bahasa merupakan kumpulan kaidah tentang struktur gramatikal bahasa.

Sejak tahun 2015 bahasa Indonesia dimasukkan ke dalam mata pelajaran wajib di tingkat Sekolah Menengah Atas (SMA) di Timor Leste. Hal tersebut merupakan keputusan dari Kementrian Pendidikan RDTL (Republik Demokratik Timor Leste). Keputusan tersebut membuka jalan bagi negara Indonesia untuk menawarkan kerjasama dalam bidang pendidikan. Pemerintah Indonesia mulai memberi bantuan tenaga pengajar bahasa Indonesia kepada beberapa sekolah yang ada di Timor Leste.

Setelah 4 tahun berselang, kerjasama antara Indonesia dan Timor Leste dalam bidang pendidikan masih berlanjut bahkan berkembang ke berbagai sektor lainnya. Hal ini menunjukkan potensi pengajaran Bahasa Indonesia di Timor Leste cukup tinggi (Handoko, Fahmi, Kurniawan, Artating, \& Sinaga, 2019) Berdasarkan keputusan Kementrian Pendidikan RDTL tentang penambahan mata pelajaran bahasa Indonesia ke dalam kurikulum pembelajaran, maka tiap-tiap sekolah berupaya untuk memenuhi standar pemerintah. Namun pada kenyataannya, pengajar bahasa Indonesia yang merupakan penduduk lokal masih menggunakan buka cetakan tahun 1960-an sebagai referensi saat mengajarkan bahasa Indonesia. 
Hal ini tentu berdampak pada penggunaan tata bahasa Indonesia oleh pemelajar Timor Leste masih terdapat banyak terdapat kesalahan.

Penggunaan tata bahasa Indonesia dalam penulisan ragam kalimat sederhana dan memenuhi standar penulisan bahasa Indonesia baku. Namun masih banyak pemelajar yang melakukan kesalahan dalam penulisan kalimat menggunakan bahasa Indonesia. Ada pun rumusan masalah yang akan dibahas dalam artikel ini adalah bagaimana implementasi penggunaan tata bahasa Indonesia dalam penulisan ragam kalimat?

Tujuan penulisan artikel ini adalah mendeskripsikan tata bahasa Indonesia secara sederhana, khususnya terkait pemilihan kata, kalimat efektif, penggunaan tanda baca, dan penggunaan huruf kapital, serta melihat implementasi penggunan tata bahasa Indonesia dalam penulisan ragam kalimat di kalangan pemelajar khususnya kelas 11 SMA Cristal. Artikel ini diharapkan dapat memberi gambaran tata bahasa Indonesia sederhana yang tepat, yang dapat digunakan dalam kehidupan sehari-hari.

\section{Metode}

Analisis penggunaan tata bahasa Indonesia dalam penulisan ragam kalimat ini dilakukan dengan metode deskriptif kualitatif. Sebagai alat bantu untuk mendeskripsikan tata bahasa Indonesia, digunakan Tata Bahasa Baku Bahasa Indonesia, Ejaan yang Disempurnakan, dan Kamus Besar Bahasa Indonesia. Implementasi penggunaan tata bahasa Indonesia dalam penulisan ragam kalimat dilihat secara acak dari tulisan 20 responden

\section{Pembahasan}

\section{Hasil}

Untuk menjawab permasalahan dalam penelitian ini dilakukan menganalisis hasil tulisan siswa membuat kalimat dalam bahasa Indonesia. Dimulai pada tanggal 25 Oktober 2019 hingga tanggal 4 November 2019, pemelajar diberikan tugas untuk menulis kembali akhir cerita dari Legenda Malin Kundang. Nilai rata-rata dari 20 responden 65 dari 100 poin, dengan nilai paling rendah 50 dan nilai tertinggi 75 .

Tabel 1. Daftar Nilai Responden

\begin{tabular}{|c|c|c|c|c|}
\hline No & Nama & Kelas & Nilai & Kutipan Tulisan Responden \\
\hline & $\begin{array}{ll}\text { Litania } & \text { C.A } \\
\text { Rosario } & \end{array}$ & ${ }_{1}^{11 \text { IPA }}$ & 5 & $\begin{array}{l}\text { Karena ibunya merasah kecewa, marah dan } \\
\text { sakit hati lalu ibunya berdoa meminta Pada Tuhan } \\
\text { agar mengutuk dia menJadi Batu... }\end{array}$ \\
\hline & $\begin{array}{ll}\text { Melusia } & \text { A.P } \\
\text { Cardinal } & \end{array}$ & ${ }_{1}^{11 \text { IPA }}$ & 5 & $\begin{array}{l}\text { Ibu Malin Kunkang Mengutuknya Karena } \\
\text { dia berkata bahwa, ibunya adalah Pengemis Yang } \\
\text { hanya mengaku-ngaku Sebagai ibunya untuk } \\
\text { mendapatkan uan lebih... }\end{array}$ \\
\hline - & $\begin{array}{ll}\text { Jimmy } & \text { Fazio } \\
\text { de Jesus } & \end{array}$ & ${ }_{1}^{11 \mathrm{IPA}}$ & 0 & $\begin{array}{l}\text { Malin kundan adalah anak durhaka yang } \\
\text { tidak mengakui ibu nia dan ia di kutuk san ibu. } \\
\text { menjadi batu... }\end{array}$ \\
\hline & $\begin{array}{l}\text { Carme Maria } \\
\text { de Deus }\end{array}$ & $2^{11 \text { IPA }}$ & 0 & $\begin{array}{l}\text { Menutuk anak nia doa ibu. nia terkabul kan } \\
\text { dan datan la fetir dan badai Yang besar. anak nia } \\
\text { menJadi batu... }\end{array}$ \\
\hline . & Dircia Amaral & $2^{11 \text { IPA }}$ & 0 & $\begin{array}{l}\text { Maling kundang tidak Mengakui Ibunya } \\
\text { sebagai ibu kandungnya Makah darih itu Ibu nya } \\
\text { sedih dan marah dan langsung berdoa Mengutuknya } \\
\text { Menjadi batu... }\end{array}$ \\
\hline & Josefina & 11 IPS & & Ceritanya Barahir Karna ibunya Berdoa \\
\hline
\end{tabular}




\begin{tabular}{|c|c|c|c|c|}
\hline - & Gama & 1 & 5 & $\begin{array}{l}\text { kepada tuha agar anaknya } . . . \text { mengubah menjadi } \\
\text { Batu...... }\end{array}$ \\
\hline & $\begin{array}{l}\text { Lediana Sales } \\
\text { Freitas }\end{array}$ & ${ }_{4}^{11 \text { IPA }}$ & 0 & $\begin{array}{l}\text { Akhir dari cerita Malin Kundang adalah, } \\
\text { istrinya Malin Kundang ingin bertemu dengan ibu } \\
\text { Malin Kundang... }\end{array}$ \\
\hline . & $\begin{array}{r}\text { Bendito } \\
\text { Viegas Galucho }\end{array}$ & $4^{11 \mathrm{IPA}}$ & 0 & $\begin{array}{l}\text { Akhir dari Cerita Maling Kundang adalah } \\
\text { Seorang ibu yang Mengutuk anaknya Menjadi } \\
\text { batu... }\end{array}$ \\
\hline • & Aida da Costa & $4^{11 \mathrm{IPA}}$ & 0 & $\begin{array}{l}\text { Akir dari Cerita Maling Kundan adalah: } \\
\text { Ibunga marah dan Mengutuk maling Kundan } \\
\text { Menjadi } \underline{\text { Batu... }}\end{array}$ \\
\hline 0. & $\begin{array}{l}\text { Marceno } \\
\text { Pereira Amaral }\end{array}$ & $4^{11 \mathrm{IPA}}$ & 5 & $\begin{array}{l}\text { Akhir dari ceritanya MAlinkundang adalah } \\
\text { dia pulang kampong terus dia ketemu ibunya... }\end{array}$ \\
\hline 1. & Daria & ${ }_{4}^{11 \mathrm{IPA}}$ & 0 & $\begin{array}{l}\text { Merasa tidak di hargai dan Kecewa, ibu nya } \\
\text { berdoa dan mengutuk nya menjadi batu dan sejak } \\
\text { itulah batu itu dinamakan MALIN KUNDANG... }\end{array}$ \\
\hline 2. & $\begin{array}{l}\text { Gabriela } \\
\text { Priska D.C.S }\end{array}$ & $2^{11 \mathrm{IPA}}$ & 0 & $\begin{array}{l}\text { Cerita terakhir Maling Kundan dia dikutuk } \\
\text { menjadi batu Karena dia tidak mengakui ibunya } \\
\text { Yang miskin... }\end{array}$ \\
\hline 3. & Ligia & $2^{11 \text { IPS }}$ & 5 & $\begin{array}{l}\text { Mali kudang Meruba Jadi batu. karna } \\
\text { ibunya berdua kepada tuhan sebat mali kudag tida } \\
\text { menhakui ibu kandungnya... }\end{array}$ \\
\hline 4. & $\begin{array}{l}\text { Fridalina } \\
\text { Saldanha }\end{array}$ & $2^{11 \text { IPS }}$ & 0 & $\begin{array}{l}\text { malin kundang berubah menjadi batu } \\
\text { karena ibunya berdoa kepada tuhan Sebab malin } \\
\text { kundang tidak mau mengakui ibunya sebagai ibu } \\
\text { kandungnya... }\end{array}$ \\
\hline 5. & Nadel Smith & $2^{11 \text { IPS }}$ & 0 & $\begin{array}{l}\text { Malinkundang menjadi Batu Karena ibunya } \\
\text { Berdoa untuk menhukum anaknya karena ibunya } \\
\text { sakit hati karena malinkundang tidak mengakuih } \\
\text { ibunya... }\end{array}$ \\
\hline 6. & $\begin{array}{l}\text { Peregrina H.P } \\
\text { de Araujo }\end{array}$ & $4^{11 \text { IPS }}$ & 5 & $\begin{array}{l}\text { Ibunya memanjatkan doa agar menghukum } \\
\text { dan mengutuk anaknya menjadi batu, doanya oun } \\
\text { dikabulkan oleh tuhan saat itu datang lah petir } \\
\text { dengan badai besar... }\end{array}$ \\
\hline 7. & $\begin{array}{l}\text { Narcizia } \\
\text { Danila I.C.S }\end{array}$ & $4^{11 \text { IPS }}$ & 0 & $\begin{array}{l}\text { Ibunya memanjatkan doa agar menhukum } \\
\text { dan mengutuk anaknya menjadi batu. doanya pun di } \\
\text { kabulkan oleh Tuhan... }\end{array}$ \\
\hline 8. & Dario & $4^{11 \mathrm{IPS}}$ & 0 & $\begin{array}{l}\text { Ibunia Memanjatkan doa agar menghukum } \\
\text { dan mengutuk anak nia Menjadi batu... }\end{array}$ \\
\hline 9. & $\begin{array}{l}\text { Sergio } \\
\text { Nelson Lay }\end{array}$ & $4^{11 \mathrm{IPS}}$ & 0 & $\begin{array}{l}\text { Akhir dari cerita Malin Kundang adalah } \\
\text { dikutuk oleh ibunya sendiri karna tidak mengakui } \\
\text { ibunya sendiri... }\end{array}$ \\
\hline 0. & $\begin{array}{ll}\text { Joao } & \text { Valente } \\
\text { da Silva } & \end{array}$ & ${ }_{1}^{11 \text { IPS }}$ & 0 & $\begin{array}{l}\text { Ceritanya Berahir karna IBunya berdoa } \\
\text { kePada tuhan untuk mengubah anaknya menjadi } \\
\text { batu... }\end{array}$ \\
\hline
\end{tabular}

Secara umum berdasarkan hasil penilaian yang dilakukan, keterampilan menulis pada pemelajar di kelas 11 SMA Cristal dapat diklasifikasikan dalam kategori cukup. Jika diperhatikan, masih terdapat banyak kesalahan dalam tulisan pemelajar kelas 11 SMA Cristal. Jika dilihat kasus per kasus, paling 
sedikit ada satu kriteria kesalahan tata bahasa Indonesia dalam tulisan yang dibuat oleh pemelajar. Kesalahan pemelajar paling banyak adalah penggunaan tanda baca, diksi, dan kalimat tidak efektif. Pemelajar tidak terbiasa menggunakan tanda baca dalam menulis kalimat. Demikian juga aspek ketepatan dalam pemilihan kata.

Secara kualitatif, telah ditemukan bahwa kelemahan utama pemelajar dalam menulis kalimat menggunakan bahasa Indonesia terletak pada penggunaan tanda baca, diksi, dan kalimat tidak efektif. Berdasarkan temuan ini diadakanlah refleksi dengan pengajar lokal. Berdasarkan refleksi yang dilakukan, diduga bahwa kondisi tersebut disebabkan oleh tidak adanya materi khusus yang mengajarkan tentang penggunaan tanda baca di tingkat Sekolah Dasar dan Sekolah Menengah Pertama.

Mata pelajaran bahasa Indonesia baru dipelajari di tingkat SMA, sementara pemelajar tidak mempelajari penggunaan tanda baca pada mata pelajaran bahasa lain seperti: bahasa Tetun dan bahasa Portugis. Pengetahuan dan teori tentang penggunaan tanda baca, baru diperoleh ketika belajar bahasa Indonesia. Ternyata tidak cukup diperoleh melalui mendengar penjelasan pengajar, melihat model tulisan yang ada, tetapi juga membutuhkan panduan khusus terkait penggunaan tanda baca.

\section{Pembahasan \\ Pilihan Kata (Diksi)}

Pilihan kata atau diksi dalam penulisan sebuah kalimat akan mempengaruhi kesan dan makna yang akan ditimbulkan. Pemilihan kata dalam satu ragam bahasa berkaitan dengan ketepatan pemilihan kata dan kesesuaian pemilihan kata.

Menurut Groys Keraf (2005:87), ketepatan pemilihan kata secara tepat berkaitan dengan menggunakan kata sesuai dengan makna yang ingin dicapai.Kesesuaian pemilihan kata berkaitan dengan suasana dan lingkungan berbahasa. Untuk membuat sebuah kalimat seorang penutur harus dapat memilih kata yang tepat dan sesuai dengan suasana dan lingkungan penutur. Dalam artikel ini, dibahas beberapa hal yang berkaitan dengan ketepatan dan kesesuaian pemilihan kata dalam kalimat, yaitu:

\section{Sinonim}

Aku tidak suka makan sayur.

Saya tidak suka makan sayur.

Baju kamu bagus sekali.

Baju Anda bagus sekali.

Sinonim merujuk pada kata-kata dengan makna (hampir) serupa. Pada contoh penggunaan sinonim di atas, dapat dipilih sesuai dengan suasana atau lingkungan penutur saat menuliskan kalimat.

Andi mengemukakan pendapatnya.

Andi mengutarakan pendapatnya.

Andi menyuarakan pendapatnya.

Supaya bahasa yang digunakan tidak monoton dapat juga dipilih sinonim kata yang penggunaannya meyesuaikan dengan konteks.

\section{Kata Indria}

Kata indria merupakan kata yang menunjukkan perasaan/pengalaman/ dengan pancaindera seperti panas, manis, dank eras. Penggunaan kata-kata indria ini dapat saling tumpang tindih, gejala ini disebut dengan sinestesia.

Aku membuat teh manis hangat untuk gadis manis yang datang sebagai tamu adikku.

\section{Kelangsungan pilihan kata}

Kelangsungan pilihan kata berkaitan kata demi kata yang dipilih sehingga dapat menyampaikan gagasan secara tepat, efektif, dan efisien. 


\begin{tabular}{|c|c|}
\hline Salah & Benar \\
\hline Merubah & Mengubah \\
\hline Dia punya ibu & Ibunya \\
\hline Banyak para konsumen & Banyak \\
& konsumen/para konsumen \\
\hline Para hadirin sekalian & Hadirin sekalian \\
\hline
\end{tabular}

\section{Kalimat Efektif}

Kalimat efektif dapat diartikan sebagai susunan kata yang mengikuti kaidah kebahasaan secara baik dan benar (sesuai EYD, Sistematis, tidak boros, dan tidak bertele-tele, setra tidak ambigu).

\begin{tabular}{|c|c|}
\hline Tidak Efektif & Efektif \\
\hline Dia yang pergi meninggalkan saya. & Dia pergi meninggalkan saya. \\
\hline $\begin{array}{l}\text { Para siswa-siswi sedang mengerjakan soal } \\
\text { ujian. }\end{array}$ & Siswa-siswi sedang mengerjakan soal ujian. \\
\hline Ibu guru masuk ke dalam ruang kelas. & Ibu guru masuk ruang kelas. \\
\hline
\end{tabular}

\section{Penggunaan Tanda Baca dan Huruf Kapital}

Dalam Pedoman Umum Ejaan Bahasa Indonesia yang Disempurnakan (2003:21) disebutka, "Huruf kapital digunakan sebagai huruf pertama unsur-unsur nama orang,awal kalimat, nama agama, nama negara, Tuhan, kitab suci, gelar, jabatan, kata ganti untuk Tuhan, dan lain-lain. Contohnya:

Makanan kesukaan saya adalah bakso, nasi Padang, dan bakmi jawa.

Semua terjadi atas kehendak-Nya.

\section{Simpulan}

Tata bahasa yang digunakan dalam menulis kalimat, menentukan perubahan maksud dan makna sebuah kalimat. Penggunaan tata bahasa yang sederhana membantu penyusunan struktur kalimat efektif. Berdasarkan permasalahan dalam penelitian ini dapat diketahui bahwa dalam penuliasan kalimat masih terdapat kesalahan dalam penggunaan tata bahasa Indonesia. Penggunaan tata bahasa Indonesia yang tidak sesuai tersebut dapat ditemukan berupa ketidaktepatan dalam penggunaan/penyusunan kata, Penggunaan tanda baca, ejaan, dan penggunaan huruf kapital.

\section{UcapanTerima Kasih}

Terima kasih penulis ucapkan kepada Kepala Pusat Pengembangan Strategi dan Diplomasi Kebahasaan (PPSDK) Prof. Emi Emilia, Ph.D., M.Ed. dan tim editor Jurnal Bahasa Indonesia bagi Penutur Asing (JBIPA) sehingga penulis dapat mempublikasikan artikel ini. 


\section{Daftar Rujukan}

Alwi, Hasan, dkk. 2003. Tata Bahasa Baku Bahasa Indonesia. Jakarta: PT. Balai Pustaka.

Harjanto.2005.Perencanan Pengajaran. Jakarta: Rineka Cipta.

Keraf, Gorys. 1996. Terampil Berbahasa Indonesia I. Jakarta: Balai Pustaka.

Keraf, Gorys. 1997. Komposisi: Sebuah Pengantar Kemahiran Bahasa. Flores: Nusa Indah.

Keraf Gorys. 2005. Diksi dan Gaya Bahasa. Jakarta: Gramedia Pustaka Utama.

Parera, Daniel.1993. Menulis Tertib dan Sistematis (Edisi Kedua). Jakarta: Erlangga

Pusat Pembinaan dan Pengembangan Bahasa, Diknas RI. 2001. Kamus Besar Bahasa Indonesia. Jakarta:Balai Pustaka.

Pusat Pembinaan dan Pengembangan Bahasa, Diknas RI. 2003. Pedoman Umum Ejaan Bahasa Indonesia yang Disempurnakan. Jakarta: Balai Pustaka.

Supriyadi, dkk.1992. Pendidikan Bahasa Indonesia 2.Jakarta: Depdikbud.

Handoko, M. P., Fahmi, R. N., Kurniawan, F. Y., Artating, H., \& Sinaga, M. S. (2019). Potensi pengembangan bahasa Indonesia menjadi bahasa internasional. Jurnal Bahasa Indonesia Bagi Penutur Asing (JBIPA), 1(1), 22-29. https://doi.org/10.26499/JBIPA.V1I1.1693 